\title{
ЦЕННОСТНО-МОТИВАЦИОННАЯ СФЕРА ЛИЧНОСТИ С ОРИЕНТАЦИЕЙ НА «ЗДОРОВЫЙ ОБРАЗ ЖИЗНИ»
}

\section{THE VALUE-MOTIVATIONAL SPHERE OF THE INDIVIDUAL WITH A FOCUS ON "HEALTHY LIFESTYLE"}

\section{Ragulina}

Summary: The article deals with the phenomenon of dependence of the individual on the attitude to a healthy lifestyle (HLS). Ordinary consciousness may think that this phenomenon has only positive properties, but in fact, when a person limits all his tasks to only one, psychologists talk about an addictive pattern. The article presents the results of studying the features of the value-motivational sphere of a healthy lifestyle-dependent personality. The author concludes that the values chosen by such a person are not particularly different from the values chosen by a person who is not prone to addiction, but the only reinforcement in their implementation is the goal of achieving the avoidance of discomfort when the behavior deviates from the social stereotype through a healthy lifestyle, which in the modern social space is such.

Keywords: healthy lifestyle (HLS), addiction, addictive behavior, HLSdependence, HLS-obsession, values, value-motivational sphere.
3 аметные изменения происходят в российском обществе, развивается совершенно новая среда обитания, новый образ жизни, часто смыслом которого является потребительское поведение, задающее свои ценностные ориентации, транслирующие определенные символы и «шаблоны» поведения, которые оказывают влияние на реакции людей. Формирование мировоззрения современного поколения происходит в условиях усиления потребительских тенденций как основы, определяющей не только внешний облик и поведение человека, но и обедненную системы целей и смыслов, где важным становиться «иметь» нечто социально одобренное. Все это приводит к тому, что в сложившихся современных условиях в молодежной среде аддиктивное поведение приобретает довольно широкие масштабы $[19,20]$.

Аддиктивное поведение широко изучено и описано такими российскими учеными как Алешиной Л.И., Дмитриевой Н.В., Егоровым А.Ю., Короленко Ц.П., Старшенбаумом Г.В. и другими $[1,3,4,5,6,9,10,11,16,18]$. К аддиктивному поведению относятся разные химические зависимости (наркомания, злоупотребление алкоголем, курение), и нехимические - игровые, расстройства пищевого поведения, всевозможные увлечения, которые пре-
Рагулина Марина Владимировна

К.nсх.н., Тихоокеанский государственный университет, 2. Хабаровск ragulina@inbox.ru

Аннотация: В статье рассматривается феномен зависимости личности от установки на здоровый образ жизни (ЗОЖ). Обыденному сознанию может казаться, что этот феномен имеет только положительные свойства, но на самом деле, когда личность ограничивает все свои задачи только одной, психологи говорят 06 аддиктивном паттерне. В статье представлены результаты изучения особенностей ценностно-мотивационной сферы 30Ж-зависимой личности. Автор делает выводы, что выбранные такой личностью ценности особенно не отличаются от ценностей, выбранных личностью не склонной к аддикции, но подкреплением в их осуществлении служит только цель достижения избегания дискомфорта при отклонении поведения от социального стереотипа через 30Ж, что в современном социальном пространстве является таковым.

Ключевые слова: здоровый образ жизни (ЗОЖ), аддикция, аддиктивное поведение, 30Ж- зависимость, 30Ж - одержимость, ценности, ценностно-мотивационная сфера.

вращаются в навязчивую идею и подчиняют все стороны жизни человека. В данной исследовательской работе мы рассматривали аддиктивное поведение, которое связано с одержимостью здоровым образом жизни.

Наиболее точно определяет аддикцию Короленко Ц.Б.: «Аддиктивное поведение (аддикция от англ, addiction - пагубная, порочная склонность) - одна из форм деструктивного поведения, которая выражается в стремлении к уходу от реальности путем изменения своего психического состояния посредством приема некоторых веществ или постоянной фиксации внимания на определенных предметах или видах деятельности, что сопровождается развитием интенсивных эмоций [9. С.9].

Содержанием феномена аддикции является прежде всего деструктивная защита от дискомфортных переживаний, искусственное изменение своего состояния, обретения безопасности, восстановление психологического равновесия.

Аддикция становится универсальным способом «бегства» от реальной действительности, и вместо гармоничного взаимодействия со всеми аспектами жизни происходит «застревание» в каком-либо одном направлении. 
В соответствии с концепцией немецкого невролога, психиатра и психотерапевта иранского происхождения $\mathrm{H}$. Пезешкиана, существует четыре вида такого «бегства»:

1) «бегство в тело» - человек всю свою активность направляет на собственное физическое или психическое усовершенствование;

2) «бегство в работу» человек «уходит» в работу, уделяет непомерное в сравнении с другими аспектами жизни время, становясь «трудоголиком»;

3) «бегство в контакты или одиночество», при котором общение становится единственно доступным способ и каналом снижения внутреннего напряжения тревоги либо единственно желанным способом удовлетворения потребностей, замещая все иные, или, наоборот, количество контактов сводится к минимуму;

4) «бегство в фантазии» - интерес к псевдофилософским исканиям, религиозному фанатизму, жизни в мире иллюзий. Человек, который ограничивает все остальные аспекты жизни, вряд ли может стать настоящим философом. Он, скорее всего будет оперировать в сознании фрагментарными кусочками книжных образов, далеких от реальности.

Такое поведение у разных людей может иметь и разную степень выраженности. В зависимости от степени выраженности начинают происходить личностные изменения в психике человека: чем сильнее аддикция, тем глубже и значительнее изменения [17].

Таким образом, создается иллюзия решения проблемы. Подобный способ борьбы с реальностью закрепляется в поведении человека и становится устойчивой стратегией взаимодействия с действительностью. Привлекательность аддикции в том, что она представляет собой путь наименьшего сопротивления. Создается субъективное впечатление, что, таким образом, обращаясь к фиксации на каких-то предметах или действиях, можно не думать о своих проблемах, забыть о тревогах, уйти от трудных ситуаций, используя разные варианты аддиктивной реализации.

Деструктивный характер аддикции проявляется в том, что она как способ личностной реализации из средства постепенно превращается в цель.

В последние годы во многих странах мира с каждым годом все больше и больше идет пропаганда здорового образа жизни. Может показаться, что ничего плохого в этом нет, человек, вроде бы, следит за собой, за своим физическим здоровьем, занимается спортом, подбирает для себя «правильный» рацион питания и т.д. Но все ли так хорошо, как кажется?
Целью нашего исследования было изучить глубинные мотивы-смыслы человека, ориентированного на «здоровый образ жизни» за пределами разумного, уже одержимого этой идеей и жертвующей во благо ее остальными сторонами своей жизни.

Современный молодой человек, желая подчеркнуть свою индивидуальность, часто, выбирая из многочисленных образцов, предложенных социумом, думает о том, как его оценят другие, получит ли он в результате этого должное признание, так как одна из задач этого возрастного периода встроиться в социум и получать свою долю ресурсов. Человек иногда теряет связь с собственным «Я», «личность» уходит на второй план, а вместо этого появляется социально одобряемая «индивидуальность» или одобряемая социальными интернетсетями форма жизни $[7,19]$.

Социальная реальность предъявляет к индивиду всё новые требования с точки зрения внешнего имиджа, внутреннего состояния, манер поведения, контакта с другими людьми. Кроме того, для подтверждения своей способности к социальному успеху необходимо предпринимать действия, которые будут видны многим. Одним из таких качеств, представляющих индивидуальность выступает тело человека.

Тело все больше выдвигается на первый план в нашем существовании, и не только как элемент действий, поступков, восприятия. Важным моментом социализации предполагается навязанная масс-медиа спортивная фигура, образ которой, по мнению известного социолога Т. Алкемайера, «... более важен, чем вся модная элегантность, которая его сопровождает. Только выставленный на показ этот образ демонстрирует свою форму и говорит про образ жизни личности, включая диету, здоровый дух, самодисциплину и волю к действию»[17. С.20].

Поэтому формирование «здорового образа жизни» (ЗОЖ) - задача не медицинская, а прежде всего воспитательная.

К сожалению, некоторые слишком увлекаются этим и заходят в одержимости здоровым образом жизни чересчур далеко. Пока что это явление или результат качественно разработанного маркетингового плана, как считают некоторые врачи и психологи, еще официально не признан болезнью, но медицина отмечает, что встречается оно все чаще.

Появился новый вид расстройства поведения - орторексия, вид психического расстройства, одержимость здоровым питанием и здоровым образом жизни. Страдают от него не только сам стремящийся к идеалу, но и его близкое окружение, родственники, которых стараются тоже вовлечь в процесс и осуждают за непонимание. 
Существует мнение, которое подтверждает наше личное наблюдение, феномен пристального внимания к телу связан с ограничением социальных контактов. 3ОЖодержимость (сегодня это термин признан и используется) проявляется в чрезмерной заботе о «теле насущном», и излишнем акцентировании на него, как на некоем объекте самолюбования и восторженного созерцания его другими людьми.

Бесконечные «селфи» молодых людей в купальниках, дискуссии о диетах в социальных сетях, проведение огромного количества времени в фитнесс-залах, чтобы вписаться в предлагаемый стандарт, все эти явления активно заполняют собой все пространства социальной жизни.

Следует иметь в виду, что от простого следования правилам здорового питания «помешанность» отличается полным отсутствием «тормозов», что можно определить по нескольким крайностям. Зависимость от такого образа существования коварна тем, что у нее есть неотразимое оправдание: «Я забочусь о своем здоровье», «Я продлеваю свою молодость», «Я держу себя в форме», «Я хочу стать лучше и красивее». Такие аргументы позитивны и имеют большую ценность в нашем обществе, то есть возразить на них становится проблематично [15].

Выделяют следующие признаки 3ОЖ - одержимости:

- Навязчивый страх. Если съесть что-то «не то», употребить больше жиров, позволить себе немного сладкого или пропустить занятия спортом, то все это превращается в страх набрать лишнего, отступить от плана, сорваться и начинать заново этот режим.

- Оперирование сложными понятиями, медицинскими процессами и математическими расчетами. Одно дело просто представить общую калорийность блюда, но чересчур является расщепление еды на все составляющие витамины, нутриенты, количество БЖУ в каждом съеденном кусочке.

- Огромные энергозатраты на ЗОЖ: значительная часть времени уходит на тренировки, размышления о сбалансированном рационе, чтение статей о здоровых методиках и также трата денег и сил на соблюдение всех правил 30Ж.

- «Классовая ненависть» как к «вредным» продуктам и явлениям, так и к людям, не соблюдающие ЗОж, ощущение своего превосходства перед «лентяями», и активное стремление вовлечь родных и друзей в свои новые интересы.

- Любое отступление от 3ОЖ-плана вызывает у вас панику, страх, отвращение к себе, тревожные навязчивые мысли «как теперь это исправить?», в общем, любую чрезмерную нервную реакцию, которая делает вас несчастной .
Увеличение ценности 30Ж может быть связано с влиянием западных норм деловой жизни, где здоровье рассматривается как качественная характеристика профессионала и успешной личности. Но такая забота не становится фактом сознания, а всего лишь остается на уровне моды. Во все времена люди воспринимали здоровье как нечто обладающее, помимо всего прочего, и ценностной значимостью, хотя ценность здоровья в разные эпохи мыслилась в кардинально различных формах. То, что отличает наше время и что, вероятно, в будущем проявится еще более отчетливо, связано с пониманием здоровья не только в негативном плане, как «здоровья от» - в смысле свободы от болезни, но и как «здоровья для» - в смысле тех возможностей действовать, реализовывать себя, которые открыты человеку, поскольку он здоров. Но еще раз обратим внимание на то, что для ЗОЖ-одержимого здоровье и красота не становиться средством к более полноценной жизни, а только цель, которой нужно добиться, чтобы соответствовать социальному стандарту, сделать «селфи» и выставить его в интернете - вот конечная цель [15].

В нашем исследовании приняло участие 50 человек: 13 юношей и 37 девушек разного возраста от 18 до 35 лет, разных профессий: профессиональные спортсмены, юристы, психологи, военнослужащие, риелторы, педагоги и др. Из них есть те, кто ведет ЗОЖ с детства, когда-то имели отношение к спорту или продолжает до сих пор, а есть и те, кто им никогда не интересовался. Формат тестирования был разный: печатный вариант и электронный, на выбор самого респондента.

Нам было необходимо выявить людей с 30Жзависимостью, определить их жизненные ценности и узнать о тех потребностях и мотивах, которые стоят за такой целенаправленностью в соблюдении 30ж, а также сравнить их результаты с результатами тех, кто свободен о каких-либо зависимостей.

В нашей работе мы использовали следующие опросники самоописания : тест на аддикцию Лозовой Г.В, который определяет склонность к 13 видам зависимостей и содержит всего 70 утверждений и ценностный опросник Шварца Ш., используемый для исследования динамики изменения ценностей как в группах (культурах) в связи с изменениями в обществе, так и для личности в связи с ее жизненными проблемами.

Опросник ценностей был разработан Шаломом Шварцем в 1992 году [8]. В ходе нашей работы разделение ценностей на социальные и личные было важным и интересным для изучения, поскольку часто личные и социально декларируемые ценности не совпадают. Опросник Шварца состоит из двух частей: первая часть опросника предназначена для изучения ценностей, идеалов и убеждений, оказывающих влияние на личность, вторая 
часть опросника представляет собой личностный профиль и можно полагать, что первая часть диагностирует социальные или декларируемые ценности, а вторая выявляет переживаемые ценности.

Нами также использовалась «Методика предельных смыслов» (МПС) Леонтьева Д.А. Она представляет собой структурированную серию вопросов и ответов, где каждый новый вопрос исходит из последнего названного ответа. Методика не имеет заранее подготовленного бланка и проводится в форме диалога индивидуально с каждым участником исследования. Серия ответов записывается на листе и впоследствии анализируется [13].

МПС была разработана автором для того, чтобы найти новые, нетрадиционные подходы к эмпирическому изучению и диагностике таких трудно поддающихся анализу структур субъективной реальности, как динамические смысловые системы сознания. В методике был воплощен сравнительно новый методический прием изучения смысловых систем через их отражение в индивидуальном мировоззрении [14].

Благодаря тому, что из процедуры проведения методики, вопросов и инструкции совсем не просто определить итоговую цель проведения исследования, испытуемому сложно заранее спланировать или изменить ответы, что частично решает проблему социальной желательности. МПС позволяет уточнять смысловое разнообразие выбираемых респондентами ценностей и обнаруживать отличие в одних и тех же выбранных номинациях.

По результатам теста Лозовой Г.В. были сформированы четыре группы респондентов с разными формами зависимости и свободных от таковой. Это отображено в таблице 1.

Таблица 1.

Группы респондентов, сформированные по тесту Лозовой Г.В.

\begin{tabular}{|l|l|l|}
\hline Группы & Наличие зависимости & Количество \\
\hline 1 группа & $30 ж$ & 9 человек \\
\hline 2 группа & 30ж + другой вид (чаще пищевая) & 4 человека \\
\hline 3 группа & Другие виды (чаще курение, алкоголь) & 18 человек \\
\hline 4 группа & Не обнаружилось & 19 человек \\
\hline
\end{tabular}

Далее по методике Шварца Ш. мы проанализировали ценности всех опрашиваемых и провели их сравнительный анализ между получившимися группами.

Результаты МПС Леонтьева представлены в виде типичных «смысловых дерев».

В первой группе конечные ответы в большинстве своем содержали идею более длительной жизни, быть подольше со своими близких. В целом, для этой группы характерны однообразные ответы с гедонистической мотивацией по Иберсолу (сам процесс жизни), а по Леонтьеву - ведущий смысл «семья»[12,13]. Мы составили типичное для этой группы «смысловое древо».

Зачем человек ведёт здоровый образ жизни?

Чтоб хорошо себя чувствовать

Чтоб меньше было проблем со здоровьем

Чтоб не уйти из жизни раньше времени

\section{Быть дольше с семьей}

\section{Потому что мы живем ради семьи.}

Вторая группа ЗОЖ-зависимых с сопутствующими химическими зависимостями отличалась тем, что наоборот приходили к ответам «ради себя», «чтобы меня долго помнили», «чтобы ощущать собственную значимость». Отличает эту группу защитная смысловая регуляции с характерными признаками мотивации личности с разными формами химических зависимостей. Общее смысловое дерево в этом случае выглядит уже иначе:

Зачем человек ведет здоровый образ жизни?

Чтоб сохранить здоровье

Чтоб счастливо жить

\section{Насытить жизнь эмоциями}

\section{Привлекать внимание других}

\section{Ощущать свою значимость}

Третья группа, где находятся участники с другими видами зависимостей, говорили об успешности, реализованности, о собственной полезности перед окружающими. И хоть у них не наблюдалось 3ОЖ-зависимости, то некоторые всё же говорили про то, что такой образ жизни может им прибавить уверенности.

И в то же время некоторые респонденты этой группы ответили, что не видят смысла в здоровом образе жизни, поскольку это «лишняя ответственность» и «вредные привычки не мешают жить». Мы видим, как будто мотивацию самореализации, но в то же время эти респонденты в самоотчете по тесту Лозовой отмечают свою склонность к злоупотреблениям курением и алкоголем, т.е. размышляют как бы вообще о полезности 30\%, не относя это к себе, следовательно считать это их смыслами не будет достоверным. А возможно, обнаруживается конфликт с желаемым образом жизни и реальным.

Зачем человек ведет ЗОЖ?

Чтоб хорошо себя чувствовать

Посвящать время любимому делу 
Наиболее типичные рейтинги ценностей и выборы в личном профиле в 4 изучаемых группах.

\begin{tabular}{|c|l|l|l|l|}
\hline Имя & \multicolumn{3}{|c|}{ Методика Шварца, ценности } \\
\hline & 1 & 2 & 3 & Профиль личности \\
\hline 1 гр. & Универсализм & Безопасность & Самостоятельность & Универсализм \\
\hline 2 гр. & Универсализм & Безопасность, самостоятельность & Безопасность, самостоятельность & Универсализм \\
\hline 3 гр. & Универсализм, самостоятельность & Безопасность, доброта & Самостоятельность & Универсализм \\
\hline 4 гр. & Универсализм & Самостоятельность & Безопасность & Самостоятельность \\
\hline
\end{tabular}

Примечание: Мы посчитали излишним размещать усредненные профили ценностных выборов личности по группам, а привели только ценности с самым высоким значением по результатам самоотчетов испытуемых.

\section{Успеть реализоваться и быть успешным}

\section{Чтоб жизнь была прожита не зря.}

Четвертая группа респондентов без зависимостей имела более длинные смысловые цепочки, содержащие и смысл «процесса жизни», предельные суждения имели философские содержания.

Зачем человек ведет ЗОЖ?

Чтоб быть здоровым и хорошо себя чувствовать

Радоваться (наслаждаться ) жизни

Быть счастливой

Осуществлять свои (цели)мечты

\section{Ни о чем не жалеть в старости}

Чтоб был смысл жить; Продолжить род; Оставить после себя след

Таблица 3.

Средняя длина смысловых цепочек по всем 4 группам.

\begin{tabular}{|l|c|c|c|c|}
\hline & 1 & 2 & 3 & 4 \\
\hline Ср. длина цепочек & 4,5 & 4,75 & 4,5 & 8,6 \\
\hline
\end{tabular}

Для расчета значимости различия количественных показателей длины смысловых цепочек использовали критерий Стьюдента для неравнозначных групп. Результаты представлены в таблице 4.

Таблица 4.

Средние значения индекса длины смысловой структуры и различия по степени выраженности этих признаков между респондентами 1 и 4 групп по t - критерию Стьюдента

\begin{tabular}{|l|l|l|l|}
\hline Индикатор & 1 группа & 4 группа & tэмп. \\
\hline IM & 4,5 & 8,6 & 3,24 при $p<.01$ \\
\hline
\end{tabular}

Наше исследование по своему формату было пилотным, т.е. его целью было проанализировать основную ценностную направленность ЗОЖ-зависимой личности, результаты позволяют сделать определенные выводы об особенностях ценностного сознания в представленных группах.

Методика Лозовой, конечно, не является безупречным клиническим инструментом для постановки диагноза, но , все же она выявляет некую сверхпредрасположенность личности к определенным формам поведения, и в психологическом плане является достаточной для того, чтобы обратить внимание на деструктивный путь самоактуализации, который на самом деле не ведет к полноценному здоровью.

Мы условно выделили два типа ценностно-мотивационной направленности сознания у личностей из разных групп. Заметно, что во всех четырех группах выборы социокультурного рейтинга ценностей самый верхний рейтинг занимает «универсализм». Напомним, что под мотивационной сферой универсализма Ш. Шварц имел в виду понимание, терпимость, защиту благополучия всех людей и природы. Мотивационные цели универсализма производны от тех потребностей выживания групп и индивидов, которые становятся явно необходимыми при вступлении людей в контакт с кем-либо вне своей среды или при расширении первичной группы.

Можно предположить, что универсализм - это, с одной стороны, как утверждал Ш. Шварц, единство с миром, а с другой стороны - это единая форма для существования всех, и прежде всего- единая форма существования тела. Если вспомнить моделей на подиуме с одинаковой походкой и выражением лица, которым подходит любая одежда, но только одного размера или солдат, марширующих на площади, которые все как один, то это будто является метафорой жизни современного человека. Вопросы безопасности существования универсализм решает легко через упрощение и стандартизацию, что мы и наблюдаем в группе 30Ж-зависимых, где мир сворачивается до пределов собственной семьи. Вторая и третья группа представляет собой варианты ценностно-смысловой организации, предполагающей обретение безопасности через универсализм (это по Шварцу непротиворечивые ценности, обеспечивающие 
неконфликтующую динамику консервативной направленности). Самостоятельность же - третья по рангу ценность в выборах испытуемых с аддиктивными формами поведения, предполагает открытость изменениям, соответственно, мы предполагаем, что в первой группе самостоятельность ограничивается рамками семьи (например, суждение «он любит поступать по-своему, на свой лад»), а во 2 и 3 группах, скорее всего это декларируемая ценность, но не воплощаемая в жизнь. В личностных профилях она набирала не более 2-3 баллов в этих группах. Что касается 3 группы, то мы видим, что мотивация безопасности связана также с таким пунктом как «доброта», расширение контактов, т.е. можно это интерпретировать, что как стратегия обеспечения безопасности она в сознании присутствует, но не проявляется в личностном профиле, т.е. как тактика не определяется, а остается только намерением.
Ценности 4 группы проявляют самостоятельность как личностное поведение, а «смысловое древо» указывает, что выбираемые ценности, находящиеся в конкурирующей позиции (универсализм, безопасность самостоятельность) обеспечивают личности некоторое напряжение выбора и действия.

Свободная от аддикции личность способна энергию внутреннего напряжения направить на реализацию широких жизненных целей, в то время как испытуемые 2 и 3 группы напряжение конфликта, порождаемое ценностными выборами реализуют лишь на погашение напряжения конфликта и самоуспокоение. Таким образом, мы можем предполагать обедненность и упрощенность ценностно-мотивационной сферы ЗОЖ-зависимой личности, что, конечно, требует дополнительного изучения.

\section{ЛИТЕРАТУРА}

1. Алешина Л.И., Маринина М.Г., Федосеева С.Ю. «Аддиктивное поведение и меры его профилактики» / Алешина Л. И., Маринина М. Г., Федосеева С.Ю. // журнал: «Грани познания». № 2(45). 2016 г. С. 124-127.

2. Баранов В.А. «Тело и телесность в социальном измерении» / Баранов В.А. // журнал: «Таврический научный обозреватель». 2016 г. С.26.

3. Галяутдинова С.И., Ахмадеева Е.В. К проблеме понимания аддикции и зависимости отечественными и зарубежными исследователями. Вестник Башкирского университета. 2013, 18 (1) - 232-235 С.

4. Дмитриева Н.В. Психология аддиктивного поведения : [монография] / Н.В. Дмитриева, Д.В. Четвериков. - Новосибирск : НГПУ, 2002.

5. Егоров А.Ю. Нехимические аддикции / А.Ю. Егоров // Аддиктология. - №1. -2008.

6. Егоров, А.Ю. Нехимические зависимости / А.Ю. Егоров. - СПб.: Речь, 2007.

7. Жураковская В.М. Индивидуальность как высший уровень развития личности // Сибирский педагогический журнал. Издательство: Новосибирский государственный педагогический университет (Новосибирск), 2008.

8. Карандашев В.Н. Методика Шварца для изучения ценностей личности: концепция и методическое руководство. — СПб.: Речь, 2004

9. Короленко Ц.П. Аддиктивное поведение. Общая характеристика и закономерности развития/ «0бозрение психиатрической и медицинской психологии. №1. 1991. С. 7-12,

10. Короленко Ц.П., Дмитриева Н.В. Психосоциальная аддиктология. Новосибирск, Издательство «0лсиб», 2012,

11. Кутбиддинова, Р.А. Психология зависимости: учебно-методическое пособие / Р.А. Кутбиддинова. - Южно-Сахалинск : СахГУ, 2017.

12. Леонтьев Д.А. Психология смысла: природа, строение и динамика смысловой деятельности. - 2019 г.

13. Леонтьев Д.А. Методика предельных смыслов (МПС): Методическое руководство. М.: Смысл, 1999

14. Леонтьев Д.А., Филатова М.А. Психологические возможности методики предельных смыслов // Вестник Московского университета. Сер. 14. Психология. 1999г. - №2- С. 53-69.

15. Мальцева И.Г. «Иллюзии современного фитнеса». / Мальцева И. Г. // «Вестник омского аграрного университета» 2015 г. С. 90 - 93.

16. Мишин А.А. Особенности проявления аддиктивного поведения // Теория и практика научных исследований: психология, педагогика, экономика и управление. 2018. №4 (4).

17. Романова Е.В. Здоровье молодежи в аспекте изучения аддиктивных форм поведения // Здоровье человека, теория и методика физической культуры и спорта, 2016. № 2. С. 14-24.

18. Старшенбаум Г.В. Аддиктология. Психология и психотерапия зависимостей: Когито-Центр; Москва; 2006

19. Урусова Е.А. Индивидуальность и самопрезентация: личность как объект и субъект потребления в современном обществе. // Журнал: Вестник Пермского университета. Философия. Психология. Социология. Издательство: Пермский государственный национальный исследовательский университет (Пермь). -2019 г.

20. Эпштейн М.Н. Философия тела / М.Н. Эпштейн. Тело свободы / Г.Л. Тульчинский. - Спб.: Алетейя, 2006. - 432 с.

(c) Рагулина Марина Владимировна (ragulina@inbox.ru). 